\title{
Satisfação no Trabalho dos Policiais Militares do Rio Grande do Sul: um Estudo Quantitativo
}

\author{
Damiana Machado de Almeida \\ Universidade Federal de Santa Maria, RS, Brasil. \\ Vania Medianeira Flores Costa \\ Universidade Federal de Santa Maria, RS, Brasil. \\ Luis Felipe Dias Lopes \\ Universidade Federal de Santa Maria, RS, Brasil. \\ Rita de Cássia Trindade dos Santos \\ Universidade Federal de Santa Maria, RS, Brasil.
}

Resumo: Satisfação no Trabalho pode ser entendida como o vínculo afetivo do indivíduo com seu ambiente laboral. A profissão de policial militar é considerada de alto risco, pois ele lida constantemente com a violência, a brutalidade e a morte. Frente a este contexto, esse estudo foi desenvolvido visando identificar o grau de Satisfação no Trabalho dos policiais militares do Rio Grande do Sul. Realizou-se uma pesquisa descritiva, do tipo survey, com abordagem quantitativa. Os participantes do estudo totalizaram 519 policiais militares pertencentes a quartéis de cidades localizadas no estado do Rio Grande do Sul. A Escala de Satisfação no Trabalho (EST) foi utilizada como instrumento de pesquisa. No geral, identificou-se que os policiais tendem a sinalizar insatisfação em relação ao trabalho. Dentre as dimensões que compõe a EST, tendem a sinalizar insatisfação em relação ao salário (média: 2,79) e com as promoções (média: 3,03); indiferença (nem satisfeitos e nem insatisfeitos) em relação à chefia (média: 4,42) e à natureza do trabalho (média: 4,37); e, por fim, sinalizam tendência à satisfação em relação aos colegas (média: 5,00). Espera-se com essas evidências contribuir para as futuras decisões organizacionais que impliquem na saúde dos policiais militares e consequente qualidade de vida, da equipe e seus familiares.

Palavras-chave: Satisfação no Trabalho, Policiais Militares, Trabalho.

\section{Job Satisfaction of the Rio Grande do Sul Military Policemen: a Quantitative Study}

\begin{abstract}
Job Satisfaction can be understood as the emotional bond of individuals with their work environment (Siqueira, 2008). The military police profession is considered a high risk one because military policemen constantly deal with violence, brutality and death (Costa, Accioly, Oliveira \& Maia, 2007). Given this context, this study was developed to identify Rio Grande do Sul military policemen's degree of satisfaction in their work. We conducted a descriptive research, survey type, with a quantitative approach. 519 military police belonging to cities barracks located in the state of Rio Grande do Sul participated. Siqueira's (2008) Satisfaction Scale at Work (EST) was used as a research tool. Overall, it was identified that policemen tend to signal dissatisfaction with work. Among the dimensions that make up the EST, they tend to signal dissatisfaction with salary (mean: 2.79) and promotions (mean: 3.03); indifference (neither satisfied nor dissatisfied) in relation to leadership (mean: 4.42) and the nature of work (mean: 4.37); and finally, they tend to signal satisfaction with colleagues (mean: 5.00). We hope that this evidence contributes to future organizational decisions involving a better health of the military policemen and, subsequently, a better quality of life, for both the team and their families.
\end{abstract}

Keywords: Job Satisfaction, Military police, Work. 


\title{
Satisfacción en el Trabajo de los Policías Militares de Rio Grande do Sul: un Estudio Cuantitativo
}

\begin{abstract}
Resumen: La satisfacción en el trabajo puede ser entendida como el vínculo emocional del individuo con su entorno de trabajo (Smith, 2008). La profesión de policía militar se considera de alto riesgo porque tiene que ver constantemente con la violencia, la brutalidad y la muerte (Costa, Accioly, Oliveira \& Maia, 2007). Teniendo en cuenta este contexto, el presente estudio fue desarrollado para identificar el grado de satisfacción en el trabajo de los policías militares de Rio Grande do Sul. Se realizó una investigación descriptiva, tipo encuesta, con un enfoque cuantitativo. Los participantes del estudio fueron 519 policías militares pertenecientes a cuarteles de ciudades ubicadas en el estado de Rio Grande do Sul. La Escala de Satisfacción en el Trabajo (EST) de Siqueira (2008) fue utilizada como herramienta de investigación. En general, se identificó que los policías tienden a indicar insatisfacción con el trabajo. Entre las dimensiones que conforman la EST, las que tienden a indicar insatisfacción son el salario (media: 2,79) y los ascensos (media: 3,03); las que tienden a indicar indiferencia (ni satisfecho ni insatisfecho) son la jefatura (media: 4,42) y la naturaleza del trabajo (media: 4,37); y, finalmente, la que tiende a indicar satisfacción es respecto a los colegas (media: 5,00). Se espera que esta evidencia contribuya a futuras decisiones organizacionales que tengan un impacto en la salud de los policías militares y en la consiguiente calidad de vida, del equipo y de sus familiares.
\end{abstract}

Palabras clave: Satisfacción en el Trabajo, Policía militar, Trabajo.

\section{Introdução}

Em virtude do contexto dinâmico e competitivo presente na sociedade moderna, o trabalho vem ocupando uma parcela cada vez maior da vida da maioria das pessoas. Inúmeros são os aspectos presentes na rotina de trabalho que influenciam diretamente o desempenho individual de cada colaborador. Quando essas influências são negativas, podem acarretar prejuízos aos indivíduos responsáveis pela execução das atividades nas organizações. As tecnologias, o ritmo de trabalho, a pressão por resultados, as relações entre a equipe, a afetividade ou a falta dela, e a estrutura de trabalho são alguns dos aspectos que atingem diretamente os indivíduos.

Nesse sentido, estudos sobre a Satisfação no Trabalho surgiram no intuito de analisar pessoas no ambiente laboral. Em meados de 1990, pesquisas reduziram a abrangência de satisfação em função de estudos sobre emoções que emergem do trabalho, buscando impulso nas pesquisas acerca de outros conceitos afetivos que são importantes para a compreensão de fenômenos relacionados ao bem-estar no ambiente laboral. Para Siqueira (2008), entende-se por Satisfação no Trabalho o vínculo afetivo do indivíduo com o seu trabalho. Para essa mesma autora, existem evidências de que a Satisfação no Trabalho está diretamente ligada a fatores sócio-organizacionais, como valores, percepções de justiça, de suporte e de reciprocidade que se estabelecem a partir das trocas entre indivíduo, colegas e organização. Sendo assim, a Satisfação no Trabalho está diretamente relacionada e dependente das políticas e práticas gerenciais da organização.

A atividade exercida pelo policial militar é de alto risco, pois está diariamente frente à violência e a brutalidade. Por conseguinte, a profissão é uma das que mais sofre influências negativas, visto que trabalha sob forte tensão em situações que colocam em risco a sua própria vida (Costa, Accioly Junior, Oliveira, \& Maia, 2007; Oliveira, \& Bardagi, 2010). Desse modo, esse estudo tem por objetivo identificar o grau de Satisfação no Trabalho na perspectiva dos policiais militares do Estado do Rio Grande do Sul.

A relevância da presente pesquisa está relacionada aos benefícios que os resultados permitirão aos gestores, policiais militares e sociedade, haja vista que o panorama relativo à Satisfação no Trabalho auxilia na implementação de estratégias e de tratamentos necessários a estes profissionais visando amenizar o rigor da profissão. Vasconcelos (2011) ratifica que, 
como os policiais são expostos a situações de vulnerabilidade, faz-se necessária a realização de pesquisas a fim de que os gestores possam conhecer e compreender as respostas do seu efetivo a traumas e a abuso de substância. Também, verifica-se a importância de novas ações no processo de formação, buscando introduzir estratégias de enfrentamento, assim como implantação de novos programas de prevenção. Além disso, a organização policial deve introduzir medidas para melhorar a imagem pública dos agentes policiais.

Por sua vez, a relevância científica da presente pesquisa se justifica na medida em que se propõe a contribuir para uma melhor compreensão sobre a satisfação no trabalho no contexto de policiais militares, preenchendo possíveis lacunas que ainda existam sobre o tema. Ainda, salienta-se que o estudo visa contribuir com subsídios sobre a temática, de modo que os seus resultados podem servir de base para a elaboração de novos estudos na área.

O presente artigo é apresentado em cinco partes. A primeira delas é a introdução, que contextualizou a pesquisa e apresentou o objetivo. Na sequência, uma breve revisão de literatura acerca da temática Satisfação no Trabalho. A terceira parte descreve o método utilizado para atingir o objetivo. Posteriormente, são discutidos os resultados encontrados e, por fim, são apresentadas as considerações finais sobre a pesquisa, enfatizando a relevância dos seus achados, assim como suas limitações.

\section{Satisfação no Trabalho}

A necessidade de compreender os fatores que influenciam pessoas no ambiente laboral fez com que o tema Satisfação no Trabalho despertasse o interesse de pesquisadores da área do comportamento organizacional. Estudiosos defendiam que a motivação dos indivíduos no ambiente de trabalho estava diretamente relacionada à satisfação, pois influenciava inúmeros comportamentos importantes para a empresa, tais como a maximização do desempenho e da produtividade; e a redução de faltas, de índices de acidentes e de rotatividade. Denota-se assim que o resultado do comportamento dos colaboradores é consequência da Satisfação no Trabalho percebida por estes (Figueiredo, 2012; Siqueira, 2008).

Figueiredo (2012) menciona que pesquisas sobre o tema, principalmente nos anos de 1970 e 1980, identificaram as dimensões que constituíam a Satis- fação no Trabalho, bem como a sua relação. Entre essas dimensões se destacam o salário, a promoção, a supervisão e o método de trabalho. No entanto, esses estudos não desprezaram variáveis como as características dos colaboradores e o contexto no qual estava sendo desenvolvido.

Há investigações que relacionam a Satisfação no Trabalho com pressupostos humanistas e sociais, os quais buscam das empresas uma maior responsabilidade social (Siqueira, \& Gomide Júnior, 2004). Para os pesquisadores, considerar que uma organização proporciona bem-estar no trabalho e valoriza a saúde ocupacional é possível a partir do monitoramento dos níveis de satisfação. De acordo com essa percepção, assume-se que os sentimentos oriundos do contexto laboral são extensivos à vida pessoal, familiar e social dos indivíduos.

Martinez e Paraguay (2002) explicam que ocorreu uma evolução no conceito do tema. Primeiramente, assumia-se que o trabalhador reagia mecanicamente a fatores externos e que o salário era o fator influenciador da satisfação. Após, surgiu a concepção que considerou a interação entre aspectos psicossociais e a subjetividade, produzindo diferentes níveis de satisfação e influenciando diretamente a qualidade de vida, o comportamento e a saúde do indivíduo, além de apresentar consequências para a organização.

Nos anos de 1990, as pesquisas focaram nas emoções provenientes do ambiente de trabalho, minimizando-se a visão abrangente das pesquisas anteriores (Gondim, \& Siqueira, 2004). Essas contribuições auxiliaram na compreensão a respeito de elementos que interferiam de maneira prejudicial na rotina laboral. Ferreira e Siqueira (2005) salientam que a definição de Satisfação no Trabalho apresenta várias abordagens. Na percepção de Spector (2012), é uma variável que retrata como a pessoa se sente em relação ao trabalho, considerando-se fatores como colegas, salário, natureza do trabalho e supervisor.

Já no século XXI, de acordo com Siqueira e Gomide Júnior (2004), a definição de satisfação se aproxima de um vínculo afetivo do indivíduo com o trabalho. Por sua vez, Siqueira (2008) explica que ela pode ser percebida na medida em que o colaborador vivencia experiências prazerosas na organização. Já Caldas, Somensari, Costa, Siqueira e Claro (2013) a consideram como um indicador de saúde.

Em outra abordagem, Rothmann e Cooper (2009) argumentam que a satisfação resulta do julga- 
mento ou da experiência de alguém. Os principais elementos que influenciam a satisfação estão relacionados às organizações, aos grupos e às pessoas. Alguns autores consideram o conceito de difícil compreensão em função da sua discricionariedade. Isso porque representa experiências e percepções do colaborador, com aspectos de sua vida individual que interferem nas condições de trabalho e repercutem na sua vida funcional (Figueiredo, 2012). A presença do sentimento de satisfação com o trabalho, na visão de Marqueze e Castro Moreno (2005), acomete diretamente o comportamento e o bem-estar do trabalhador, incorrendo em diferentes consequências, tanto pessoais quanto profissionais.

Siqueira (2008) chama atenção para que, até o momento, as pesquisas pouco contribuíram para explicar as variações nos níveis de satisfação, apenas revelavam características pessoais dos trabalhadores e do ambiente físico. Estudos no Brasil, segundo esta mesma autora, identificaram expressiva influência dos fatores do contexto sócio-organizacional, como valores, percepção de justiça, suporte e reciprocidade nas relações de trocas sociais e econômicas entre os colaboradores e a empresa.

Percebe-se assim que, por meio desta abordagem, é viável identificar o quanto a organização está interessada em proporcionar um ambiente agradável aos seus colaboradores. Logo, devem ser pautas constantes nas políticas e práticas gerenciais, prioritariamente as que envolvem a distribuição de retornos. Assim, denota-se que, ao perceber os efeitos que alguns fatores ocasionam nos níveis de Satisfação no Trabalho, o gestor poderá conduzir melhor as diversas situações, de maneira a maximizar a eficiência de seu grupo de trabalho e, por consequência, elevar o desempenho de sua instituição.

Inúmeros pesquisadores elaboraram e validaram diferentes instrumentos para mensurar a satisfação no trabalho, entre os quais Martins e Santos (2006), que mencionam que o mais antigo é o de Brayfield e Rothe, de 1951, um dos mais utilizados e com maior impacto na literatura da área. Por sua vez, Spector (2012) argumenta que outro modelo relevante é o Índice Descritivo do Trabalho (IDT), de Smith, Kendall e Hullin, de 1969, tendo em vista sua elevada utilização em estudos científicos. Esse instrumento é composto por cinco dimensões: trabalho, salário, oportunidades de promoção, supervisão e colegas de trabalho.

Em relação à abrangência, o instrumento Job Diagnostic Survey (JDS), elaborado por Hackman e
Oldham em 1976, se destaca na mensuração do nível de Satisfação no Trabalho (Valle, 2007). Com de 83 questões, ele é do tipo Likert de sete pontos e identifica cinco fatores denominados de características essenciais ao cargo: variedade de habilidades, identidade da tarefa, significância da tarefa, autonomia e feedback.

No cenário brasileiro, o Questionário de Medida de Satisfação no Trabalho (QMST), foi um dos primeiros instrumentos elaborados e validados no contexto nacional, por Siqueira em 1978 (Neves, 2012). Sua validação resultou em 80 itens e sete fatores: satisfação geral, desgaste físico e psicológico, status da função, localização da empresa, benefícios compensadores, reconhecimento e desenvolvimento pessoal.

Outro instrumento disponível para mensurar a satisfação no ambiente de trabalho foi a Escala de Satisfação no Trabalho (EST), desenvolvida por Siqueira (2008), a qual detém uma visão multidimensional. Nessa abordagem, o tema se refere ao quanto de vivências prazerosas o indivíduo percebe na instituição. O modelo é composto por cinco dimensões, visando compreender a origem de tais experiências prazerosas, analisando a satisfação dos indivíduos com: o salário, os colegas, a chefia, as promoções e o próprio trabalho.

Depreende-se assim que, por intermédio da avaliação da Satisfação no Trabalho, é possível verificar se a instituição investe no bem-estar de seus colaboradores. Isso porque se torna perceptível o quanto cada dimensão propicia ao colaborador sentimentos positivos. Na Figura 1 estão demonstradas as cinco dimensões da EST desenvolvida por Siqueira (2008).

Siqueira (2008) argumenta que os aspectos que a teoria aponta como dimensões do conceito de satisfação são os mais relevantes no instrumento para medir Satisfação no Trabalho. A escala tem uma simplificada aplicação, que possibilita aos trabalhadores responderem às indagações da pesquisa de modo tranquilo. Assim, os resultados obtidos com a aplicação deste instrumento viabilizam tanto análises científicas como gerenciais.

Outra característica essencial da EST de Siqueira (2008) que contribuiu para sua escolha no presente estudo foi sua adaptabilidade à realidade pesquisada, até mesmo por já ser validada no Brasil. Outro fator que determinou sua preferência foi sua concisão, haja vista que um instrumento de pesquisa extenso poderia prejudicar o tempo de concentração para determinar a resposta que melhor representa a situação em cada questão da respectiva dimensão. 


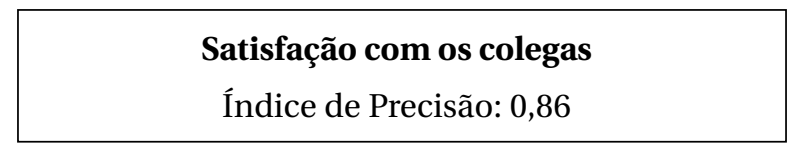

\section{Satisfação com o salário}

Índice de Precisão: 0,92

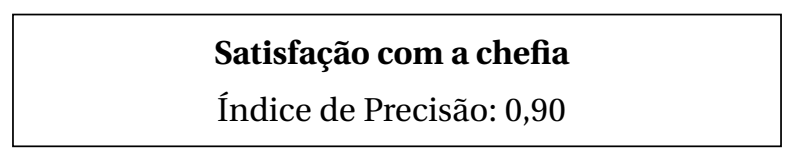

\section{Satisfação com a natureza do trabalho}

Índice de Precisão: 0,82

\section{Satisfação com as promoções}

Índice de Precisão: 0,87
Contentamento com a colaboração, a amizade, a confiança e o relacionamento mantido com os colegas de trabalho.

Contentamento com o que recebe como salário se comparado com o quanto o indivíduo trabalha, com sua capacidade profissional, com o custo de vida e com os esforços feitos na realização do trabalho.

Contentamento com a organização e a capacidade profissional do chefe, com o seu interesse pelo trabalho dos subordinados e entendimento entre eles.

Contentamento com o interesse despertado pelas tarefas, com a capacidade destas em absorver o trabalhador e com a variedade delas.

Contentamento com o número de vezes que já recebeu promoções, com as garantias oferecidas a quem é promovido, com a maneira da empresa em realiza as promoções e com o tempo de espera por estas.

Figura 1

Dimensões da Escala de Satisfação no Trabalho.

Logo, a compreensão dos níveis de Satisfação no Trabalho contribui para que a instituição obtenha um maior grau de eficiência em um contexto que se mostra cada vez mais propenso a interferências físicas e emocionais. De acordo com Rothmann e Cooper (2009), a insatisfação acarreta aspectos negativos, como absenteísmo, rotatividade de pessoal, além de baixo desempenho do colaborador.

\section{Método}

Realizou-se uma pesquisa descritiva em que os dados foram coletados, registrados e analisados de forma a compreender o ambiente dos policiais militares frente à de Satisfação no Trabalho. Segundo Souza, Santos e Dias (2013) e Barros e Lehfeld (2000), esse tipo de pesquisa visa a verificação e a transcrição das características de determinado cenário, grupo ou o estabelecimento de relações entre variáveis sem a interferência do autor.

Quanto à abordagem, os procedimentos adotados foram de natureza quantitativa. Segundo Shaghnessy, Zechmeister e Zechmeister (2012), a pesquisa quantitativa é utilizada em estudos cujos resultados são decorrentes principalmente de análises estatísticas. Desse modo, é possível inferir que a pesquisa quan- titativa se adapta em situações nas quais a população estudada é significativamente numerosa. Do mesmo modo, esta abordagem tem a pretensão de garantir resultados e evitar distorções de análise e de interpretação, proporcionando uma margem maior de segurança quanto às inferências.

A pesquisa realizada foi do tipo survey, que, conforme Babbie (2001), "permite enunciados descritivos sobre alguma população, isto é, descobrir a distribuição de certos traços e atributos. O pesquisador não se preocupa com o porquê da distribuição existir, mas como que ela é” (p. 96). O autor ainda reforça que a pesquisa survey demonstrou atender o objetivo da pesquisa, apresentando o cenário atual da Brigada Militar no Estado do Rio Grande do Sul no que se refere à verificação do grau de Satisfação no Trabalho.

\section{Participantes}

Participaram 381 indivíduos, sendo que, em relação ao posto de trabalho que os policiais pesquisados ocupam, a maioria, 305 (58,76\%), é soldado, 198 $(38,15 \%)$ são sargentos, oito $(1,54 \%)$, tenentes, quatro $(0,77 \%)$, capitães, dois $(0,39 \%)$, sub-tenentes e dois $(0,39 \%)$ policiais não responderam. 
Para o cálculo da amostra do estudo foi adotada a fórmula estatística para população finita, com base em Lopes et al. (2008), considerando-se um erro amostral de $5 \%$ e um nível de $95 \%$ de confiança dos dados. Numa população de 33.650 policiais militares, o tamanho da amostra é de, no mínimo, 381 indivíduos. A coleta de dados possibilitou a constituição de uma amostra de 519 policiais militares, que trabalham efetivamente em 97 municípios do Estado do Rio Grande do Sul. Para a escolha dos Policiais Militares, a amostragem foi não probabilística e por conveniência, uma vez que a inclusão de cada participante foi de acordo com a disponibilidade no dia e horário determinado pela Brigada Militar para a aplicação.

Em relação aos aspectos éticos, a pesquisa foi registrada no Gabinete de Projetos (GAP) do Centro de Ciências Sociais e Humanas (CCSH) da Universidade Federal de Santa Maria (UFSM) sob o número de projeto 036461. Posteriormente, o projeto foi encaminhado ao Comando Geral da Brigada Militar do Estado para registro, avaliação e liberação. Por fim, obteve-se o registrado no Sistema Nacional de Ética em Pesquisa (SISNEP) sob o certificado de apresentação para apreciação ética (CAAE) de no 31304914.4.0000.5346.

\section{Instrumentos}

Para avaliar a Satisfação no Trabalho, foi utilizada a EST, composta por 25 itens, a qual foi validada por Siqueira (2008). A EST analisa o contentamento no trabalho a partir de cinco dimensões, cada uma com cinco itens: satisfação com os colegas de trabalho, satisfação com o salário, satisfação com a chefia, satisfação com a natureza do trabalho e satisfação com as promoções.

\section{Procedimentos}

A coleta dos dados ocorreu em 97 municípios aos quais os pesquisados estão efetivamente alocados. Este número se justifica pelo fato de que os mesmos estavam temporariamente deslocados para o município de Porto Alegre (RS), alguns com o objetivo de participar do curso preparatório para sargentos e outros, para garantir a ordem na capital durante o período das eleições. Além destes, participaram policiais de 17 municípios da região central do Estado do Rio Grande do Sul, que compõem o $1^{\circ}$ Regimento de Polícia Montada ( $\left.1^{\circ} \mathrm{RPMON}\right)$.

\section{Análise dos Dados}

Após a coleta, os dados foram organizados em uma planilha eletrônica que perfez o banco de dados que, posteriormente, foi analisado eletronicamente com o auxílio do programa Statistical Package for Social Sciences (SPSS, versão 21). Apresentado o percurso metodológico adotado e o modo como foram analisados os dados, passa-se para apresentação e análise dos resultados obtidos.

\section{Resultados e Discussão}

Neste tópico estão dispostos os resultados do presente estudo, sendo que, em primeiro instante, expõe-se uma breve caracterização do perfil pessoal e ocupacional dos 519 respondentes. Em segundo momento, aborda-se o grau de Satisfação no Trabalho encontrado no contexto estudado de acordo com as dimensões do instrumento de pesquisa.

\section{Caracterização do Perfil dos Participantes}

Os participantes da pesquisa totalizaram 519 policiais militares do Estado do Rio Grande do Sul. A síntese dos principais dados pessoais e ocupacionais dos pesquisados, podem ser visualizados na Tabela 1 .

Pode-se afirmar que a amostra do presente estudo é predominantemente do gênero masculino, com idade de 31 anos ou mais, com estado civil casado, com apenas um filho e, quanto à escolaridade, a maioria detém ensino médio completo. Já quanto aos dados ocupacionais, é possível perceber que o perfil da amostra do presente estudo é predominantemente constituído por policiais militares que possuem de 21 a 30 anos $(31,98 \%)$ de atuação na Brigada Militar, graduados no posto de soldado $(58,76 \%)$, os quais exercem atividades externas $(42,58 \%)$, possuem renda entre 1 a 3 salários mínimos (52,41\%) e dividem igualmente a responsabilidade pela manutenção financeira da família com outra pessoa $(35,45 \%)$.

\section{Grau de Satisfação no Trabalho e suas Dimensões}

Para a interpretação dos resultados da EST, Siqueira (2008) orienta que seja considerada a média classificada da seguinte maneira: valores entre 1 e 3,9 tendem a sinalizar insatisfação; entre 4 e 4,9 
informam um estado de indiferença, ou seja, nem satisfeitos e nem insatisfeitos; e valores entre 5 e 7 tendem a indicar satisfação. A Tabela 2 apresenta a estatísticas descritivas da Satisfação no Trabalho e das respectivas dimensões.

A média geral da EST foi de 3,92, o que demonstra que, de acordo com a interpretação da classificação sugerida por Siqueira (2008), os policiais militares participantes da pesquisa tendem a sinalizar insatisfação em relação ao trabalho. Para Robbins, Judge e Sobral (2010), o trabalho vai além da execução das atividades no qual o indivíduo é responsável. Depende também da forma como o indivíduo avalia ou percebe as suas relações com colegas, com chefia, obediência a regras e políticas organizacionais, desempenho, aceitação das condições de trabalho, entre outros aspectos que compõe o contexto laboral.
Marqueze e Castro Moreno (2005) explicam que "a insatisfação pode gerar prejuízos à saúde física, mental e social, acarretando problemas à organização e ao ambiente de trabalho" (p. 77). As autoras também alertam para a necessidade de se adotar medidas coletivas para amenizar os problemas decorrentes da insatisfação. Dentre elas se destacam: adequação do salário à função exercida, plano de carreira, aumento das oportunidades de atividades de esporte e lazer, programas de interação social, formação de uma equipe de saúde ocupacional para avaliar as situações de risco e adoção de medidas preventivas.

Para Robbins, Judge e Sobral (2010), a insatisfação dos funcionários se expressa de diversas maneiras, entre elas estão: comportamento com foco ao abandono da empresa, incluindo a busca de um novo emprego e a demissão (saída); tentativa construtiva

Tabela 1

Principais dados pessoais e ocupacionais do perfil dos pesquisados.

\begin{tabular}{lll}
\hline Dados & & \multicolumn{1}{c}{ Resultados } \\
\hline Pessoais & Gênero & Masculino (83,43\%) \\
& Faixa de Idade & 31 anos ou mais $(66,47 \%)$ \\
& Estado civil & Casado $(72,45 \%)$ \\
& Filhos & Possui filhos (67,63\%) \\
& Número de filhos & Um filho (42,45\%) \\
& Escolaridade & Ensino Médio (59,15\%) \\
Ocupacionais & Tempo de atuação & 21 a 30 anos (31,98\%) \\
& Posto & Soldado (58,76\%) \\
& Atividade & Externa (42,58\%) \\
& Renda & 1 a 3 salários mínimos \\
& Grau de responsabilidade pela manutenção & Divide igualmente as responsabilidades com \\
& financeira da família & outra pessoa (35,45\%) \\
\hline
\end{tabular}

Tabela 2

Estatísticas descritivas da Satisfação no Trabalho e das respectivas dimensões.

\begin{tabular}{lcc}
\hline \multirow{2}{*}{ Modelos teóricos } & \multicolumn{2}{c}{ Estatísticas } \\
\cline { 2 - 3 } & Média & Desvio padrão \\
\hline Escala de Satisfação no Trabalho de Siqueira (2008) & 3,92 & 1,45 \\
Satisfação com os colegas & 5,00 & 1,24 \\
Satisfação com o salário & 2,79 & 1,61 \\
Satisfação com a chefia & 4,42 & 1,41 \\
Satisfação com a natureza do trabalho & 4,37 & 1,33 \\
Satisfação com as promoções & 3,03 & 1,66 \\
\hline
\end{tabular}


de melhorar as condições da empresa, apresentando sugestões de melhorias, discutindo os problemas com os superiores e exercendo formas de atividade sindical (comunicação); espera passiva, porém otimista de que a situação melhore, defendendo a empresa em relação às críticas e acreditando que os dirigentes da empresa irão optar pelo melhor para a empresa (lealdade); e deixar a situação piorar, incluindo absenteísmo e atrasos, aumento do índice de erros, redução do empenho (negligência).

Segundo Minayo e Adorno (2013), existem diversas causas para a insatisfação dentro das corporações, tais como: a frustração e ressentimento pela falta de reconhecimento dos superiores e da população; as queixas sobre salários; as condições de trabalho; a qualidade de vida; o descontentamento com a justiça e o fato de se sentirem permanentemente ameaçados. Ainda segundo os mesmos autores, as autoridades deveriam levar em consideração a existência de resistência e descontentamento dos policiais, uma vez que a valorização e a satisfação são pré-requisitos para a segurança e a proteção da população.

Analisando a Tabela 2, percebe-se que, nas dimensões que compõe a EST, os policiais tendem a sinalizar: insatisfação em relação ao salário (média: 2,79) e com as promoções (média: 3,03); indiferença (nem satisfeitos e nem insatisfeitos) em relação à chefia (média: 4,42 ) e a natureza do trabalho (média: 4,37); e, por fim, sinalizam tendência à satisfação em relação aos colegas (média: 5,00). Esses dados são temerários, visto que os policiais pesquisados apresentam tendência à satisfação em apenas uma das cinco dimensões analisadas.

Esses resultados vão ao encontro da afirmação de Robbins, Judge e Sobral (2010) de que a insatisfação com os salários e com as possibilidades de promoção são as questões que mais aparecem nas pesquisas sobre Satisfação no Trabalho. Além da tendência de insatisfação com o salário, a de insatisfação com as promoções também foi identificada. Nesse sentido, Chanlat (2005) afirma que os indivíduos que fazem parte de uma organização merecem explicações a respeito das promoções, além de um processo de promoção equitativo e claro.

Já os resultados da pesquisa de Lelis (2013) com gestores da área comercial indicaram que as dimensões relacionadas à satisfação com os colegas, satisfação com a chefia, satisfação com as promoções e satisfação com a natureza do trabalho foram classificadas como estado de indiferença, ou seja, nem satisfeitos e nem insatisfeitos. No entanto, a dimensão relacionada à satisfação com o salário indicou insatisfação por parte dos pesquisados. Esses resultados diferem dos encontrados na presente pesquisa no que diz respeito à satisfação com os colegas que os policiais militares registraram estar satisfeitos e em relação às promoções que apresentaram insatisfação. As demais dimensões da satisfação estão de acordo com os achados.

Da mesma forma, Garrido (2009), ao pesquisar a Satisfação no Trabalho dos servidores do Superior Tribunal de Justiça (STJ), identificou que os pesquisados estão satisfeitos em relação às dimensões satisfação com a chefia e satisfação com os colegas de trabalho. Já a respeito das dimensões: satisfação com a natureza do trabalho, satisfação com o salário e satisfação com as promoções, demonstraram indiferença, isto é, nem satisfeitos e nem insatisfeitos. Tais resultados diferem dos encontrados na presente pesquisa, sendo que, em relação à satisfação com a chefia, os policiais militares registraram indiferença e, a respeito da satisfação com o salário e com as promoções, demonstraram insatisfação. As demais dimensões (satisfação com a natureza do trabalho e satisfação com os colegas) apresentaram o mesmo resultado da pesquisa de Garrido (2009).

Sendo assim, percebe-se a necessidade de mais estudos a respeito de tais dimensões contemplando diferentes públicos a fim de identificar os fatores e os processos que conduzem a satisfação, a indiferença, ou a insatisfação. Na Tabela 3, visualiza-se a média geral encontrada para a cada dimensão do modelo, bem como a de seus itens.

\section{Satisfação com os Colegas}

Conforme é possível visualizar na Tabela 3 a média geral encontrada para a dimensão satisfação com os colegas foi de 5,00 , classificando-os como satisfeitos com os colegas de trabalho. Ao pesquisar a Satisfação no Trabalho de gestores da área comercial de vários Estados do Brasil, Lelis (2013) registrou média de 4,70 para a dimensão satisfação com os colegas, sendo esta a dimensão com a maior média em seu estudo. Figueiredo (2012) contribui afirmando que o "suporte social no local de trabalho proporciona ao indivíduo uma proteção frente à intensificação de estressores do cotidiano laboral, pois além de influenciar emoções positivas, favorece também a resolução de problemas que estão além da capacidade individual" (p. 127). 
Tabela 3

Estatísticas descritivas das cinco dimensões da Escala de Satisfação no Trabalho.

\begin{tabular}{|c|c|c|c|}
\hline Modelo Teórico & $\begin{array}{l}\text { Itens do questionário } \\
\text { No meu trabalho atual, sinto-me... }\end{array}$ & Média & $\begin{array}{l}\text { Desvio } \\
\text { Padrão }\end{array}$ \\
\hline \multirow{6}{*}{$\begin{array}{l}\text { Satisfação com } \\
\text { os colegas }\end{array}$} & 1. Com o espírito de colaboração dos meus colegas de trabalho. & 4,65 & 1,36 \\
\hline & 6. Com o tipo de amizade que meus colegas demonstram por mim. & 5,11 & 1,20 \\
\hline & 14. Com a maneira como me relaciono com os meus colegas de trabalho. & 5,29 & 1,09 \\
\hline & 17. Com a quantidade de amigos que eu tenho entre meus colegas de trabalho. & 5,15 & 1,23 \\
\hline & 24. Com a confiança que eu posso ter em meus colegas de trabalho. & 4,83 & 1,32 \\
\hline & Satisfação com os colegas (geral) & 5,00 & 1,24 \\
\hline \multirow{6}{*}{$\begin{array}{l}\text { Satisfação com } \\
\text { o salário }\end{array}$} & 5. Com o meu salário comparado com o quanto eu trabalho. & 2,92 & 1,68 \\
\hline & 8. Com o meu salário comparado à minha capacidade profissional. & 2,92 & 1,67 \\
\hline & 12. Com o meu salário comparado ao custo de vida. & 2,47 & 1,53 \\
\hline & $\begin{array}{l}\text { 15. Com a quantia em dinheiro que eu recebo desta empresa ao final de } \\
\text { cada mês. }\end{array}$ & 2,82 & 1,57 \\
\hline & 21. Com meu salário comparado aos meus esforços no trabalho. & 2,82 & 1,62 \\
\hline & Satisfação com o salário (geral) & 2,79 & 1,61 \\
\hline \multirow{6}{*}{$\begin{array}{l}\text { Satisfação com } \\
\text { a chefia }\end{array}$} & 2. Com o modo como meu chefe organiza o trabalho do meu setor. & 4,26 & 1,39 \\
\hline & 9. Com o interesse de meu chefe pelo meu trabalho. & 4,22 & 1,35 \\
\hline & 19. Com o entendimento entre mim e meu chefe. & 4,61 & 1,41 \\
\hline & 22. Com a maneira como meu chefe trata-me. & 4,57 & 1,40 \\
\hline & 25. Com a capacidade profissional do meu chefe. & 4,46 & 1,49 \\
\hline & Satisfação com a chefia (geral) & 4,42 & 1,41 \\
\hline \multirow{6}{*}{$\begin{array}{l}\text { Satisfação com } \\
\text { a natureza do } \\
\text { trabalho }\end{array}$} & 7. Com o grau de interesse que minhas tarefas me despertam. & 4,76 & 1,26 \\
\hline & 11. Com a capacidade de o meu trabalho absorver-me. & 4,07 & 1,30 \\
\hline & 13. Com a oportunidade de fazer o tipo de trabalho que faço. & 4,61 & 1,36 \\
\hline & 18. Com as preocupações exigidas pelo meu trabalho. & 4,00 & 1,43 \\
\hline & 23. Com a variedade de tarefas que realizo. & 4,41 & 1,31 \\
\hline & Satisfação com a natureza do trabalho (geral) & 4,37 & 1,33 \\
\hline \multirow{6}{*}{$\begin{array}{l}\text { Satisfação com } \\
\text { as promoções }\end{array}$} & 3. Com o número de vezes que já fui promovido nessa empresa. & 3,25 & 1,80 \\
\hline & 4. Com as garantias que a empresa oferece a quem é promovido. & 3,62 & 1,63 \\
\hline & 10. Com a maneira como esta empresa realiza promoções de seu pessoal. & 2,83 & 1,63 \\
\hline & 16. Com as oportunidades de ser promovido nesta empresa. & 2,98 & 1,66 \\
\hline & $\begin{array}{l}\text { 20. Com o tempo que eu tenho de esperar para receber uma promoção } \\
\text { nesta empresa. }\end{array}$ & 2,44 & 1,57 \\
\hline & Satisfação com as promoções (geral) & 3,03 & 1,66 \\
\hline
\end{tabular}

Já ao analisar por itens da escala, se constata que a maior parte dos pesquisados se sentem satisfeitos com a maneira como se relacionam com os colegas de trabalho (item 14, média: 5,29), com a quantidade de amigos que tem entre os colegas de trabalho (item 17, média: 5,15$)$ e com o tipo de amizade que os colegas demonstram (item 6, média: 5,11). Assim, entendese que os policiais pesquisados se sentem satisfeitos com a forma como se relacionam com os colegas, assim como com a quantidade de amigos oriundos do ambiente de trabalho e com o tipo de amizade que os colegas demonstram sentir por ele.

Em contrapartida, dois itens apresentaram tendência à indiferença por parte dos pesquisados, isto é, não estão nem satisfeitos e nem insatisfeitos, em relação: à confiança que eu posso ter em meus 
colegas de trabalho (item 24, média: 4,83) e ao espírito de colaboração dos meus colegas de trabalho (item 1, média: 4,65). Por fim, destaca-se que, na dimensão satisfação com os colegas, nenhum item foi classificado com tendência à insatisfação. Quanto aos desvios padrão, no geral e por item, foram baixos, variando de 1,09 a 1,36, indicando pouca variabilidade na opinião dos respondentes.

\section{Satisfação com o Salário}

Também na Tabela 3, constata-se que a média geral encontrada para a dimensão satisfação com o salário foi de 2,79, sendo assim, os pesquisados demonstram estar insatisfeitos com o salário. Tal índice vai ao encontro dos resultados encontrados por Lelis (2013), que, ao pesquisar a Satisfação no Trabalho de gerentes da área comercial de vários Estados do Brasil, obteve uma média de 3,83 para a dimensão salário, indicando também tendência à insatisfação.

Nesta dimensão da EST é possível identificar que os cinco itens apresentam insatisfação por parte dos pesquisados. A maior média foi registrada no item 5 , referente à relação do salário com o quanto trabalha (média: 2,92) e no item 8 que compara o salário com a capacidade profissional (média: 2,92). Após, estão o item 15 com média 2,82 - quantia de dinheiro que o pesquisado recebe no final de cada mês - e o item 21 também com média de 2,82 - salário com os esforços que o policial executa no trabalho. E por último, o item 12 com média de 2,47, que compara o salário com o custo de vida.

Corroborando estes achados, ao pesquisar a Satisfação no Trabalho de bibliotecários de uma Instituição Federal de Ensino Superior (IFES), Figueiredo (2012) também identificou que os trabalhadores se encontram insatisfeitos com a remuneração recebida e que se sentem indiferentes quanto à busca de melhorias para sanar tal insatisfação. Segundo a autora, isso se deve ao fato de que são funcionários públicos e de que as suas mobilizações, como greves, não têm produzido efeito.

\section{Satisfação com a Chefia}

Na Tabela 3, verifica-se que a média geral da dimensão satisfação com a chefia foi de 4,42 , registrando tendência à indiferença, isto é, não estão satisfeitos e nem insatisfeitos com a chefia. Analisando os itens que compõe esta dimensão, percebe-se que os cinco apresentam a mesma classificação de tendência à indiferença. Os policiais pesquisados apresentam tendência à indiferença em relação: ao modo como o chefe organiza o trabalho do setor do pesquisado (item 2, média: 4,26); ao interesse do chefe pelo trabalho do pesquisado (item 9, média: 4,22); ao entendimento entre o pesquisado e o chefe (item 19, média: 4,61 ); à maneira como o chefe trata o pesquisado (item 22, média: 4,57); e à capacidade profissional do chefe (item 25, média: 4,46).

Achados de Figueiredo (2012) apontam que os servidores públicos da IFES pesquisada mostram-se satisfeitos com a sua chefia, apresentando médias dos itens da dimensão entre 5,22 e 5,65. Isso demonstra existir satisfação, de um modo geral, em relação à chefia, mas também em relação aos cinco itens que compõem tal dimensão. Ao relacionar os achados da presente pesquisa, se verifica que esta dimensão merece atenção por parte do comando da Brigada Militar, pois caso não ocorra interferência para reverter esse quadro, no caso de aumentar para o grau de insatisfação com a chefia, pode acarretar prejuízos à instituição.

\section{Satisfação com a Natureza do Trabalho}

Ainda verificando os dados da Tabela 3, percebe-se que a satisfação com a natureza do trabalho obteve média de 4,37, indicando tendência à indiferença, assim como os cinco itens que compõe essa dimensão. Para os policiais pesquisados é indiferente: a satisfação em relação ao grau de interesse que as tarefas despertam nele (item 7, média: 4,76); o respeito da capacidade que o trabalho tem de absorvê-lo (item 11, média: 4,07); e a oportunidade de fazer o tipo de trabalho que o policial faz (item 13, média: 4,61). Os policiais pesquisados também apresentam tendência à indiferença quanto às preocupações exigidas pelo trabalho (item 18, média: 4,00 ) e com a variedade de tarefas que realizam (item 23, média: 4,41).

Fraga (2006) esclarece que "a atividade-fim do policial, o policiamento ostensivo, é exercida pelo policial fardado, em locais públicos, com caráter preventivo, pela observação e fiscalização, com a atitude de vigilância, tentando coibir a ação de infratores e evitar a ocorrência de atos delituosos" (p. 6). O autor explica ainda que o trabalho do policial militar possui características próprias, tais como: a falta de uma jornada fixa com horários predeterminados; 
compromisso de dedicação exclusiva; exposição a intempéries ao realizar o policiamento ostensivo; e constante exposição à violência. Além das questões legais da profissão, exige também iniciativa, sensatez e capacidade de negociação em situações adversas. Ao comprometer-se com a profissão, o policial não pode se omitir frente a fatos que exijam a sua intervenção, devendo estar sempre preparado para servir a sociedade.

Por fim, é possível identificar ainda na Tabela 3 que a média geral referente à dimensão satisfação dos policiais pesquisados em relação às promoções foi de 3,03, ou seja, uma tendência à insatisfação, da mesma forma os cinco itens que a compõe.

A média mais baixa, isto é, o item que apresenta o maior grau de insatisfação, foi em relação ao tempo que o policial necessita aguardar para receber as promoções (item 20, média: 2,44), seguido da maneira como a corporação realiza as promoções dos policiais (item 10, média: 2,83), e das oportunidades de ser promovido (item 16, média: 2,98). Os policiais também apresentam tendência à insatisfação a respeito do número de vezes que já foi incorreu em promoções (item 3, média: 3,25 ) e das garantias que a corporação oferece a quem é promovido (item 4, média: 3,62).

Corroborando com tais achados de Figueiredo (2012), em suapesquisa com bibliotecários de uma Instituição Federal de Ensino Superior (IFES), a dimensão satisfação com as promoções foi a que demonstrou a menor média indicando insatisfação entre os pesquisados, em que o item 20 (média: 3,56) - tempo de espera para receber uma promoção nesta empresa - e o item 10 (média: 3,67) - maneira como esta empresa realiza promoções de seu pessoal - também evidenciaram os maiores níveis de insatisfação. Esses dados sugerem, no caso da presente pesquisa, a necessidade de mudanças e ajustes por parte do governo estadual visando à satisfação dos policiais militares em relação ao seu trabalho e a carreira militar.

A partir da análise das dimensões que compõem a Satisfação no Trabalho de policiais militares, percebe-se que os mesmos apresentam tendência à satisfação em relação aos colegas, indiferença (nem satisfeitos e nem insatisfeitos) em relação à chefia e à natureza do trabalho, e insatisfação em relação ao salário e às promoções. Dessa forma, o comando da Brigada Militar poderá se beneficiar deste diagnóstico, visto que terá a informação a respeito dos pontos mais críticos, possibilitando traçar estratégias para reverter tal resultado, maximizando então os índices de satisfação destes profissionais.

\section{Síntese dos Principais Resultados e Sugestões de Melhorias}

Diante desta apresentação sobre os resultados obtidos e discutidos com a literatura sobre o tema Satisfação no Trabalho cabe identificá-los de modo resumido, considerando os pontos fortes, oportunidades de melhorias e pontos fracos, conforme a Tabela 4.

Na Tabela 4 está disposta a síntese dos principais resultados obtidos no presente estudo, destacando os pontos fortes, que são aqueles percebidos como favoráveis, as oportunidades de melhorias que se referem aos aspectos que poderão ser melhorados, e os pontos fracos, que são aqueles identificados como desfavoráveis. Todos os aspectos citados devem ser monitorados constantemente e servem de subsídios para traçar estratégias visando manter os pontos fortes, potencializar as oportunidades de melhorias e reverter os resultados dos pontos fracos, tornando-os também pontos fortes.

Com base nos dados da Tabela 4 , foram propostas estratégias no intuito de auxiliar na adequação desses resultados ao contexto organizacional pesquisado:

- Plano de Carreira: elaborar, em conjunto com representantes da Associação dos Sargentos, Subtenentes e Tenentes da BM (ASSTBM), um plano de carreira baseado nos conhecimentos, habilidades e atitudes, visando à valorização profissional e consequentemente da imagem da profissão;

- Plano Salarial: elaborar e atualizar constantemente um plano salarial em consonância com o plano de carreira, considerando as peculiaridades da profissão, e considerando também programas de incentivo;

- Proporcionar eventos de integração dos policiais e seus familiares nos próprios quartéis, a fim de divulgar e valorizar a atividade profissional;

- Organizar atividades que proporcionem e incentivem as relações de cooperação entre os comandos e a sua equipe;

- Elaborar um projeto que vise melhorar a imagem pública dos policiais militares; 
- Programa de Treinamento: implementar ações de treinamento e desenvolvimento adequados as necessidades da Brigada Militar e realizar constante avaliação dos resultados;

- Implantar programa efetivo de comunicação interna, utilizando ferramentas como correio eletrônico, buscando agilizar o trâmite das informações;

- Proporcionar, aos policiais com cargo de liderança, treinamento constante para melhorar a gestão de pessoas. Para isso, sugere-se contrato com instituições de ensino de nível superior.

Tabela 4

Síntese dos principais resultados obtidos.

\begin{tabular}{llc}
\hline $\begin{array}{l}\text { Pontos fortes } \\
\text { Aspectos identificados como favoráveis }\end{array}$ & Média \\
\hline $\begin{array}{l}\text { Satisfação com os } \\
\text { colegas }\end{array}$ & A maneira como se relaciona com os colegas & 5,29 \\
& A quantidade de amigos entre os colegas de trabalho & 5,15 \\
& O tipo de amizade que os colegas demonstram & 5,11 \\
\hline $\begin{array}{l}\text { Oportunidades de melhorias } \\
\text { Aspectos que podem ser melhorados (média) }\end{array}$ & 4,83 \\
\hline $\begin{array}{l}\text { Satisfação com os } \\
\text { colegas }\end{array}$ & A confiança que tem entre os colegas de trabalho \\
Satisfação com a & O espírito de colaboração dos colegas de trabalho \\
chefia & O entendimento entre o chefe e os subordinados & 4,65 \\
& A maneira como o chefe trata os subordinados & 4,61 \\
& A capacidade profissional do meu chefe & 4,57 \\
Satisfação com a & O modo como o chefe organiza o trabalho do setor & 4,46 \\
natureza do trabalho & A interesse do chefe pelo trabalho dos subordinados & 4,26 \\
& A variedade de tarefas que realiza & 4,22 \\
& A capacidade de o trabalho absorver & 4,61 \\
& As preocupações exigidas pelo trabalho & 4,41 \\
& O grau de interesse que as tarefas despertam & 4,07 \\
\hline
\end{tabular}

Pontos fracos

Aspectos que foram identificados como desfavoráveis (média)

\begin{tabular}{llc}
\hline Satisfação com o & O salário comparado com o quanto trabalha & 2,92 \\
& O salário comparado à capacidade profissional & 2,92 \\
& A quantia em dinheiro que recebe no final de cada mês & 2,82 \\
& O salário comparado aos esforços no trabalho & 2,82 \\
& O salário comparado ao custo de vida & 2,47 \\
Satisfação com as & As garantias que a brigada militar oferece a quem é promovido & 3,62 \\
promoções & O número de vezes que foi promovido & 3,25 \\
& As oportunidades de ser promovido na brigada militar & 2,98 \\
& A maneira como a brigada militar realiza promoções de seu pessoal & 2,83 \\
& O tempo que tem que esperar para receber uma promoção na brigada militar & 2,44 \\
\hline
\end{tabular}




\section{Considerações Finais}

Ao analisar o grau de Satisfação no Trabalho foi possível identificar, de um modo geral, o predomínio de insatisfação dos pesquisados em relação ao trabalho. Quanto às dimensões que compõem esse modelo teórico, registrou-se insatisfação em relação ao salário e a promoções na carreira; sinalizaram indiferença (nem satisfação e nem insatisfação) em relação à chefia e também a respeito da natureza do trabalho; e satisfação com os colegas de trabalho.

Dessa forma, sugere-se que o comando da Brigada Militar interceda buscando reverter tais resultados no que se refere, principalmente, ao salário e às promoções, no qual interferem diretamente na (des) valorização de tais profissionais, pois estes foram os pontos que se sobressaíram. Isso também se aplica na relação dos policiais militares com a chefia e também com a natureza do seu trabalho.

Finalizando, aponta-se como uma das limitações desse estudo a dificuldade em comparar os achados obtidos no presente estudo com outras pesquisas sobre tal temática, e especificamente com policiais militares. Esta carência se dá principalmente devido ao fato da coleta dos dados ter ocorrido em apenas um estado do Brasil, de modo que a generalização dos resultados é restrita a realidade do Estado do Rio Grande do Sul. Sugere-se, para estudos futuros, replicar esta pesquisa com uma amostra nas diversas

\section{Referências}

Babbie, E. (2001). Métodos de pesquisas de Survey. Belo Horizonte, MG: UFMG.

Barros, A. J. S., \& Lehfeld, N. A. S. (2000). Fundamentos de metodologia científica. São Paulo, SP: Pearson.

Caldas, C. B., Somensari, P., Costa, S. N., Siqueira, M. M. M., \&Claro, J.A.C.S. (2013). Satisfação e engajamento no trabalho: docentes temáticos e auxiliares da EAD de universidade privada brasileira. Gerais: Revista Interinstitucional de Psicologia, 6(2), 225-237. Recuperado de http://pepsic.bvsalud.org/scielo.php?script=sci_arttext\&pid=S1983-82202013000200006

Chanlat, J. F. (2005). Mitos e realidades sobre o estresse dos gerentes. In: Davel, E., \& Melo, M. C. O. L. Gerência em ação: singularidades e dilemas do trabalho gerencial. Rio de Janeiro, RJ: Editora FGV.

Costa, M., Accioly Junior, H.; Oliveira, J., \& Maia, E. (2007). Estresse: diagnóstico dos policiais militares em uma cidade brasileira. Revista Pa- regiões brasileiras, e até mesmo em outros países, a fim de realizar análises comparativas.

O tipo de abordagem de pesquisa também é um fato limitador visto que se fez uso apenas da abordagem quantitativa em um corte transversal. Sugere-se também que estudos futuros adotem a abordagem qualitativa aliada à abordagem quantitativa, podendo realizar entrevistas com uma amostra do contingente militar, a fim de identificar possíveis peculiaridades que não foram percebidas no presente estudo. No mesmo sentido, é importante que se realize esta mesma pesquisa sob um viés longitudinal, pois este tipo de abordagem possibilita acompanhar o desenvolvimento e a mudança no grau de Satisfação no Trabalho.

As considerações e limitações encontradas nesse estudo servem como ponto de partida para o desenvolvimento de novos estudos sobre as temáticas e o público em questão. Tais investigações são necessárias devido à carência que há em estudos empíricos na área.

Ao finalizar esse estudo, espera-se que a sua realização, além de contribuir para estudos futuros, possa ser útil como instrumento de apoio para as futuras decisões organizacionais no que tange as evidências encontradas, contribuindo para a efetiva saúde dos policiais militares e consequente qualidade de vida, da equipe e seus familiares.

namericana de Salud Pública, 21(4), 217-222. doi:10.1590/S1020-49892007000300004

Ferreira, M. L. C. B., \& Siqueira, M. M. M. (2005). Antecedentes de Intenção de Rotatividade: estudo de um modelo psicossocial. Organizações em Contexto, 1(2), 47-67. doi:10.15603/1982-8756/roc.vln2p\%20 47\%20-\%2067

Figueiredo, J. M. (2012). Estudo sobre a satisfação no trabalho dos profissionais de informação de uma IFES. (Dissertação de mestrado). Universidade Federal Fluminense, Rio de Janeiro, RJ.

Fraga, C. K. (2006). Peculiaridades do trabalho policial militar. Textos \& Contextos, 5(2). 1-19. Recuperado de http://revistaseletronicas.pucrs.br/ojs/index. $\mathrm{php} /$ fass/article/view/1033/812

Garrido, T. C. J. (2009). Satisfação no trabalho: um estudo no superior tribunal de justiça. (Monografia de especialização). Universidade de Brasília, Brasília, DF. 
Gondim, S. M. G., \& Siqueira, M. M. M. (2004). Emoções e afetos no trabalho. In J. C. Zanelli, J. E.Borges-Andrade, \& A.V. B. Bastos (Orgs.), Psicologia, organizações e trabalho no Brasil (285-315). Porto Alegre, RS: Artmed.

Lelis, J. W. F. (2013). Estresse e satisfação no trabalho de profissionais que exercem a função de gestores na área comercial (Dissertação de mestrado). Pontifícia Universidade Católica de São Paulo, São Paulo, SP.

Lopes, L. F. D., Muller, I., Souza, A. M., Ansuj, A. P., Moraes, D. A. O., Moreira Junior, F. J. et al. (2008). Estatística geral: caderno didático (3a ed.). Santa Maria, RS: UFSM.

Marqueze, E. C., \& Castro Moreno, C. R. (2005). Satisfação no trabalho: uma breve revisão. Revista Brasileira de Saúde Ocupacional, 30(112), 69-79. doi:10.1590/S0303-76572005000200007

Martinez, M. C., \& Paraguay, A. I. B. B. (2002). As relações entre a satisfação com aspectos psicossociais no trabalho e a saúde do trabalhador (Dissertação de mestrado). Faculdade de Saúde Pública da Universidade de São Paulo, São Paulo, SP.

Martins, M. C. F., \& Santos, G. E. (2006). Adaptação e validação de construto da Escala de Satisfação no Trabalho. Psico-USF, 11(2), 195-205. doi:10.1590/S1413-82712006000200008

Minayo, M. C. S., \& Adorno, S. (2013). Risco e (in)segurança na missão policial. Ciência \& Saúde Coletiva, 18(3), 585-593. doi:10.1590/S1413-81232013000300002

Neves, V. F. (2012) Impacto da satisfação no trabalho e da percepção de suporte organizacional sobre a Sindrome de Burnout em trabalhadores de enfermagem de um hospital universitário. (Dissertação de Mestrado em Psicologia Aplicada, Universidade Federal de Uberlândia).

Oliveira, A. L. M., \& Bardagi, M. P.(2010). Estresse e comprometimento com a carreira em policiais militares. Boletim de Psicologia, 59(131), 153-166. Recuperado de http://pepsic.bvsalud.org/scielo.php?script=sci_arttext\&pi$\mathrm{d}=$ S0006-59432009000200003

Robbins, S. P., Judge, T. A., \& Sobral, F. (2010). Comportamento organizacional: teoria e prática no contexto brasileiro (14a ed.). São Paulo, SP: Pearson Prentice Hall.
Rothmann, I., \& Cooper, C. (2009). Fundamentos de psicologia organizacional e do trabalho. Rio de Janeiro, RJ: Elsevier.

Shaghnessy, J.J., Zechmeister, E.B., \& Zechmeister, J. S. (2012). Metodologia de pesquisa em psicologia (9a ed.). Porto Alegre, RS: AMGH.

Siqueira, M. M. M. (2008). Satisfação no trabalho. In Siqueira, M. M. M. (Org.). Medidas do comportamento organizacional: ferramentas de diagnóstico e de gestão. Porto Alegre, RS: Artmed.

Siqueira, M. M. M., \& Gomide Júnior, S. (2004). Vínculos do indivíduo com o trabalho e com a organização. In Zanelli, J. C., Borges-Andrade, J. E., \& Bastos, A. V. B. (Orgs.). Psicologia, organizações e trabalho no Brasil. Porto Alegre: Artmed.

Souza, G. S., Santos, A. R., \& Dias, V. B. (2013). Metodologia da pesquisa científica: a construção do conhecimento e do pensamento científico no processo de aprendizado. Porto Alegre, RS: Animal.

Spector, E. P. (2012). Psicologia nas organizações (4a ed.). São Paulo, SP: Saraiva.

Valle, A. R. (2007). Monitoramento da satisfação no trabalho em uma empresa financeira (Tese de doutorado). Universidade de Brasília, Brasília, DF.

Vasconcelos, T. S. (2011). Programas de gerenciamento do estresse e qualidade de vida no trabalho na área de segurança pública. In A. M. Rossi, P. L. Perrewé, \& J. A. Meurs (Org.), Stress e qualidade de vida no trabalho: stress social: enfrentamento e prevenção. São Paulo, SP: Atlas.

\section{Damiana Machado de Almeida}

Doutoranda pela Universidade Federal de Santa Maria, Santa Maria - RS, Brasil.

E-mail: dimyalmeida@gmail.com

\section{Luis Felipe Dias Lopes}

Doutor pela Universidade Federal de Santa Catarina, Florianópolis - SC. Docente da Universidade Federal de Santa Maria, Santa Maria - RS, Brasil.

E-mail: lflopes67@yahoo.com.br

\section{Vania Medianeira Flores Costa}

Doutora pela Universidade Federal da Bahia, Salvador - BA. Docente da Universidade Federal de Santa Maria, Santa Maria - RS, Brasil.

E-mail:vania.costa@ufsm.br 
Rita de Cássia Trindade dos Santos

Mestranda pela Universidade Federal de Santa Maria, Santa Maria - RS, Brasil.

E-mail: rita.santos0606@gmail.com

Jonathan Saidelles Corrêa

Mestrando pela Universidade Federal de Santa Maria, Santa Maria - RS, Brasil.

E-mail: jonathan.saidelles@gmail.com

Endereço para envio de correspondência:

Av. Roraima n 1000 - Prédio 74C-Sala 4303 Bairro Camobi

Santa Maria - RS

CEP: 97105-900

Recebido 27/01/2016

Reformulação 22/08/2016

Aprovado 04/11/2016

Received $01 / 27 / 2016$

Reformulated $08 / 22 / 2016$

Approved 11/04/2016

Recibido 27/01/2016

Reformulado $22 / 08 / 2016$

Aceptado 04/11/2016

Como citar: Almeida, D. M., Lopes, L. F. D., Costa, V. M. F, Santos, R. C. T., \& Corrêa, J. S. (2016). Satisfação no trabalho dos policiais militares do Rio Grande do Sul: um estudo quantitativo: um estudo quantitativo. Psicologia: Ciência e Profissão, 36(4): 801-815. doi:10.1590/1982-3703000362016

How to cite: Almeida, D. M., Lopes, L. F. D., Costa, V. M. F., Santos, R. C. T., \& Corrêa, J. S. (2016). Job satisfaction of the Rio Grande do Sul military policemen: a quantitative study. Psicologia: Ciência e Profissão, 36(4): 801-815. doi:10.1590/1982-3703000362016

Cómo citar: Almeida, D. M., Lopes, L. F. D., Costa, V. M. F., Santos, R. C. T., \& Corrêa, J. S. (2016). Satisfacción en el trabajo de los policías militares de Rio Grande do Sul: un estudio cuantitativo. Psicologia: Ciência e Profissão, 36(4): 801-815. doi:10.1590/1982-3703000362016 